Price, 25 Cents.

2

POULTRY COMPENDIUM.

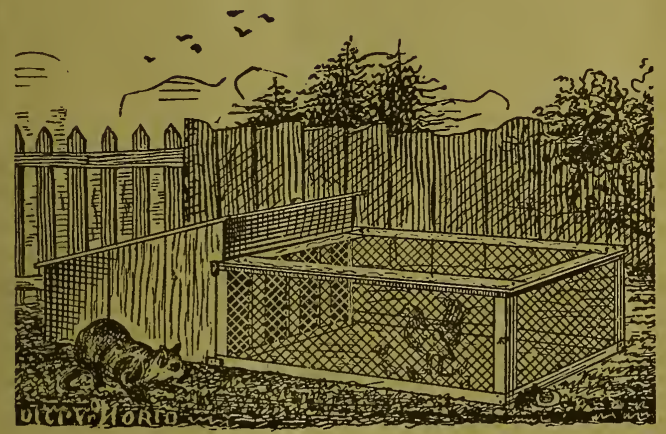

BEING A BRIEF TREATISE

ON THE

Rearing and Management of Domestic Fowls, ${ }^{\mathrm{BX}}$

H. S. BABCOCK.

HARTFORD, CONN. 1885. 

A

\section{POULTRY COMPENDIUM,}

BEING A

\section{BRIEF TREATISE}

ON THE

REARING AND MANAGEMENT

OF

\section{DOMESTIC FOWLS,}
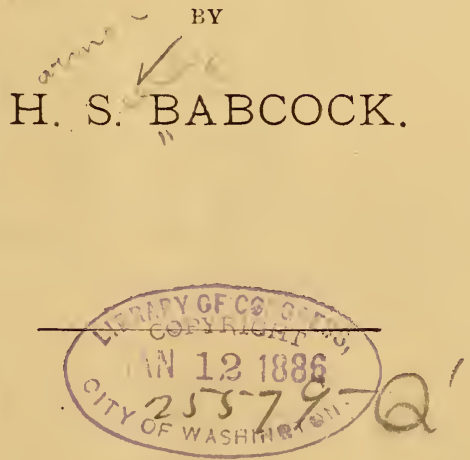

HARTFORD, CONN. 1885. 
$S=48$

B12

Copyright, r 885 , by H. S. BABCOCK. 


\section{A POULTRY COMPENDIUM.}

\section{$\ldots \cdots$ \\ INTRODUCTORY.}

THE poultry business is complex. It reaches out in 1 many directions, and has many aims and ends. Those engaged in it, however, may be conveniently arranged in six classes, according to the purposes to be accomplished; and the beginner should determine to which class he belongs, in order to pursue his business to the greatest advantage and achieve the highest success in it. These classes comprise those who are engaged in:

r. Raising poultry for market.

2. Producing eggs for market.

3. Supplying fowls and eggs for home consumption.

4. The production of superior breeding stock.

5. Experimental crossing, and the production of new breeds.

6. Keeping fowls for pets.

A person may follow the purpose indicated in any one of these classes exclusively, or he may unite two or more of them. For example, a person may raise poultry and produce eggs for market, or he may devote himself to one of these objects alonc. Generally he succeeds the best, who is willing to concentrate all his ef- 
forts to the accomplishment of one thing. It requires courage to do it, but it is the shortest road to success. There may be "no royal road to learning," but "do one thing with all your might," is the royal road to success.

Some breeds are better suited to one class, some to another; hence the necessity of knowing something about the different breeds. To engage in the poultry business without such knowledge would be about as wise as to go to sea without chart or compass. You might, in either case, arrive safely in port, and you might be dashed to pieces upon some unknown reef. A classification of breeds may be roughly made. This classification will not be found to be exclusive, for the breeds, like the purposes which the breeder may have, will overlap each other, but for general purposes this classification will probably be found sufficiently accurate. It is not designed to be exhaustive, and only a few representative breeds are enumerated.

First Class. In this class belong those varieties of fowls which grow rapidly, fatten easily, attain good weight, and have, when such qualities can be united with the others, yellow legs and a yellow skin. The Dorkings, Plymouth Rocks, Cochins, Brahmas, Houdans, La Fleche, Langshans and others will be found suitable for this class.

Second Class. In this class eggs are considered everything; chickens are viewed as accidents or incidents. The hens which, so to speak, "lay an egg on every day, and two on Sunday," and pursue this commendable course for the greater part of the fifty-two weeks in each year, are: demanded. They are generally non-sitters, a trait of great importance in this connection. Their keeper only 
desires to raise enough chickens to replace one-half or three-fourths of his stock; for he finds that part pullets and part hens pay best, taking summer and winter together. Leghorns and Hamburgs fill the bill, while Plymouth Rocks, Houdans and Langshans are also desirable.

Third Class. Here is needed what is known as "the general-purpose fowl," "the combination fowl," and so on; that is, a fowl which unites in itself, in a high degree of excellence, the various qualities which distinguish other varieties. The laying qualities of the Leghorns, the table qualities of the Dorkings, the quiet disposition of the Asiatics, the beauty of the Games, are all desired in one fowl. Such a fowl has not yet been found, and there is no probability of its ultimate discovery. The quest has proved and will prove a fruitless one. But yet some varieties do unite laying qualities, table excellencies, quiet dispositions and great beauty in so high a degree that they serve to keep alive the hope in not a few breasts that eventually one fowl will be found possessing every desirable quality. Prominent among these varieties are the Plymouth Rocks, Dorkings and American Dominiques.

Fourth Class. To this class belongs any breed in which the fancier is specially interested, and which has, as all breeds have to a greater or less degree, valuable qualities. Utility is to be preferred to beauty, but the two are not to be deemed antagonistic, but, on the contrary, are to be united as far as possible, as they have been, for instance, in the production of that noble fowl, the Colored Dorking, and in that popular breed, the Wyandotte.

Fifth Class. To this class belong all the breeds; both 
useful and ornamental, to be used as the knowledge and skill of the breeder may suggest. Here is a field wide in extent and fascinating in character. The possibilities of modifications of form and plumage, the effects produced by judicious selection of specimens, careful matings of sexes, and wise crossings of breeds, make this both a useful and delightful field to explore. When we consider that the gigantic Light Brahma and the diminutive Game Bantam, the pure White Leghorn and the jet-black Langshan, the clean-headed Game and the tufted and bearded Polish, ard the almost innumerable variety of markingslacings, barrings, spanglings - the different breeds display, all came from one variety of fowls, we begin to realize somewhat of the extent and interest of this field. Some of the best crosses for practical purposes, which have yet been made, are the White Leghorn and Light Brahma, the Brown Leghorn and Partridge Cochin, the Black Spanish and Plymouth Rock, the Colored Dorking and Dark Brahma, and the White Leghorn and Langshan. The products of these crosses have been excellent fowls for general purposes-good layers, good table fowls, etc. Sixth Class. This class is a wide one. To it belong those fowls which are preëminent for beauty of plumage, elegance of figure, and the possession of crests and appendages which excite admiration or awaken wonder in the beholder. Here we find the beautiful Polish fowls, with their rose-like crests and depending beards; the clean cut, high-stationed, glistening-plumaged Games, which are the creme de la creme of the fancy; the little Bantams, with their important ways, the incarnation of strut and pomposity, of whose appearance one can never tire; 
the Fur fowls, whose feathers excite your curiosity and wonder; the Rumpless fowls, that seem as if the Creator had started to make a model and had dropped it from his hands in an unfinished state, that remind you, by way of contrast, of the familiar quotation, "thereby hangs a tail," their tails being lost like those of little Bo-Peep's sheep; the Frizzles, which look as if they had been caught out in a cyclone-the storm striking them in the rearand had not had time since then to arrange their disordered garments; and many others that, by their appearance and ways, have been universally pronounced desirable for pets.

It may not be unwise to caution the beginner against starting with too many varieties. I know that this is an oft-told tale, that "line upon line, precept upon precept, here a little and there a little," have been given upon this subject by our faithful poultry journals, a copy of one of which, at least, and more, if he can afford, ought to be in the hands of every breeder, whether veteran or beginner. And I know that this valuable advice is not always followed. There is need of constantly sounding the warning, until beginners are able to overcome the seductions of the many breeds, and like a faithful lover remain true to one. One feels in full sympathy, while considering this subject, with that clergyman who preached from his pulpit the same sermon week after week, until at last he was waited upon by a committee of the church to expostulate with him for such a proceeding. His justification was briefly given: "I saw," he said, "that you had not acted upon the advice I gave, and I am determined to preach that sermon until its suggestions are 
followed." When beginners will select one breed and stick to it until the difficulties of breeding it to a high standard are overcome, until, we may say, the breed is mastered, then it will be time to cease warning them against too many breeds; but until that time comes, every writer upon poultry, who does his full duty, will send out this warning cry: "One breed, enough-more breeds, too many; one breed, success-many breeds, failure."

\section{POULTRY-HOUSES AND YARDS.}

The purpose having been settled and the breed selected, before purchasing the fowls it becomes necessary for their would-be owner to provide a suitable place in which to keep them.

Select for the site of your poultry-house and yard a dry soil. Dampness causes or intensifies that scourge of poultry, the roup; it renders cleanliness next to impossible, and is indirectly the fruitful mother of a variety of diseases. If the soil is not naturally dry, drain it, and make it as dry as possible. Then do not commit the too common error of setting your house so low that the first rain will cause a miniature flood, and make the inside of your fowl-house resemble a duck pond. Set your house above the natural level of the soil and fill up to it, so that the land will slope from it each way, and form a good watershed. Dry earth used within the house, scattered over the floors, helps to render the atmosphere dry, besides being an admirable absorbent of those gases which are a valuable component part of fertilizers, but deadly to your stock.

Secure sunlight. Let your fowl-house face the south, 
with southeril and eastern windows. You cannot overestimate the value of sunlight for your fowls. Diseases, like wicked men, "love the darkness rather than light, because their deeds are evil." Sunlight, with its bright lances, will put to flight that dire army, led by roup, whose aides de camp are colds, catarrhs, rheumatic affections, diarrhea, and cholera.

Provide shade. If you doubt the need of this, stand for a half hour, without hat or other protection, unc.s the blazing rays of a July or August sun, and after this experience, if you do not die from a sun-stroke, think how your fowls would enjoy protection from the vertical rays of "the too-near-approaching sun." Trees are best, but boxes and boards may be propped up, and will afford a satisfactory substitute.

Don't forget fresh air, or, in other words, provide suitable ventilation. A direct draft should be avoided at all times, but fresh air and means for the escape of foul gases must be provided. The want of fresh air leads to a weakened state of the constitution, the blood fails to be properly aerated and becomes thick, dark and sluggish; hens cease to lay, contagious and epidemic diseases break out among them, and the loss of a part, or the whole, of the flock ensues. And all this because fresh air was not provided!

Cleanliness is necessary, both for the comfort of the fowls and of their owner. Buildings should be so arranged as to be easily cleaned. Dry earth should be provided for the floors, it being one of the best deodorizers known, Filth produces vermin, vermin produces disease, and disease produces death. 
Convenience should be sought after. "Time is money;" therefore, build so as to save time. A few dollars more spent in making a house convenient is money well invested; it will pay large dividends in actual gain, not only of time, but of money itself. For, if things are convenient to clean they will be kept clean, and cleanliness is, as we know, absolutely essential to success.

A cheap and convenient poultry-house, to accommodate from twelve to twenty fowls, suitable for one or

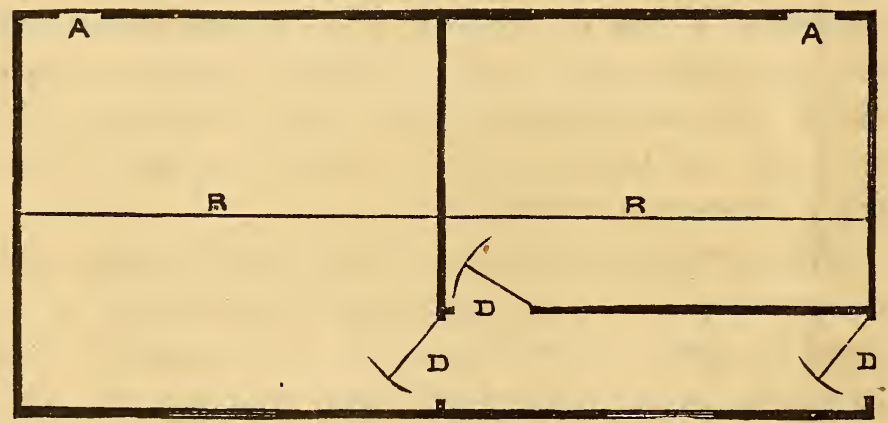

Fig. 1 .

two breeds, may be built as follows: Fig. I represents the ground plan of the house, which is 16 feet long by 8 feet wide, making two rooms for the hens, one $6 \times 8$ and the other $8 \times 8$. An entry or hall $2 \times 8$ runs along the building, so that doors communicate with both rooms. This hall can be used for the storing of grain, and nest boxes can be arranged along it, so that the eggs can be gathered without entering the room where the fowls are kept: A A represent the small doors through which the fowls pass into their yards. $R \mathrm{R}$ represent roosts, and 
D D D the doors of the building. Beneath the roosts a board to catch droppings may be placed. The floor is to be boarded, or to be of dry earth, as the builder may desire.

Fig. 2 represents the front elevation, which is seven feet high; the rear is five feet in height. The windows should be provided with wire netting, so as to open and allow a free circulation of air through the house. "This is specially necessary during the summer season.

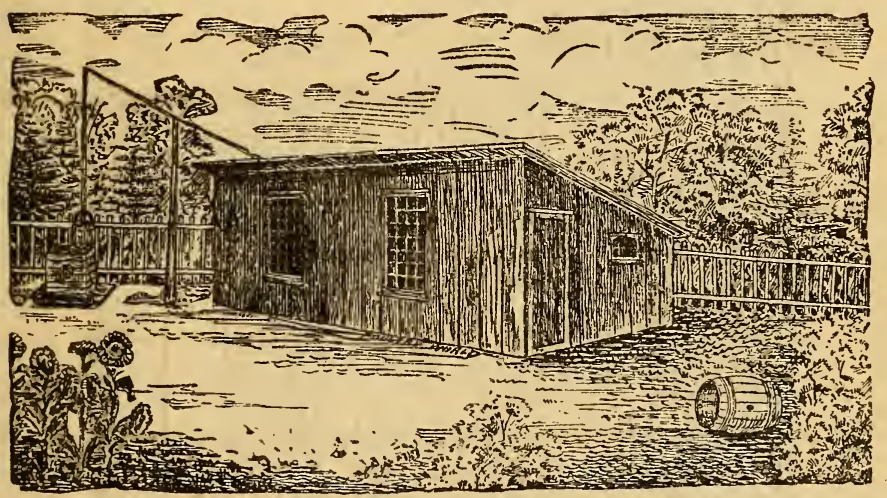

Fig. 2.

Fig. 3 shows an end elevation, (the opening of the small sliding window to be covered with wire netting, for the purpose of securing ventilation.)

The house in this plan, drawn for my own use, is designed to face the east. If you can give a southern exposure, let the small doors A A be placed beneath the large windows.

The bill of lumber needed will be as follows: For frame, rafters, etc., $\mathrm{I} 87$ feet spruce; covering, 400 feet 
hemlock, $35^{\circ}$ feet spruce, and enough shingles for roof; add to this the cost of lining with tarred paper. The lumber bill will not be far from $\$ 20$; with windows; perhaps $\$ 25$. Any one who has any mechanical ingenuity can build it. The dimensions will be found to be such that lumber can be cut without waste.

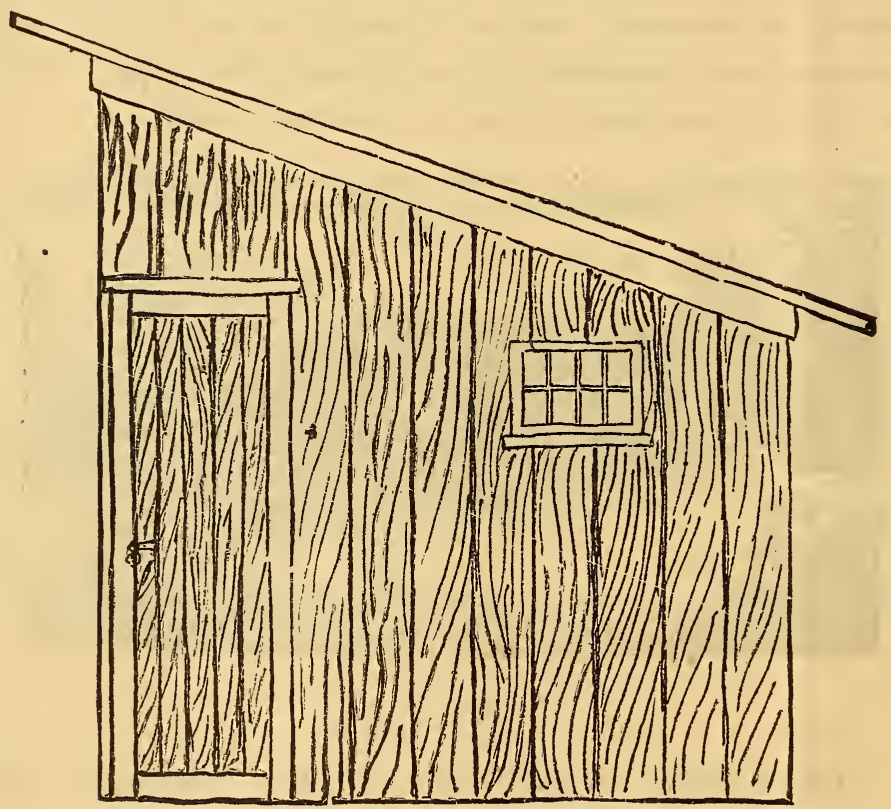

Fig. 3.

A house very similar to the above, except that the. hallway is omitted, stands upon my grounds. The dimensions are ro by $\mathrm{I} 2$ feet; the front of the house is 9 feet in height, the rear 7 feet in height; it has a shed roof made of matched pine boards, the joints put together with white lead, and the building, roof and all, has received two good coats of paint. The frame, 
except the sills which are chestnut, is of spruce. The first or inside boarding is of hemlock nailed with planed side in. This is covered with heavy tarred paper, and the paper is in turn covered with matched pine boards. There are two large windows made in one sash (ordinary storm sashes) and fitted to slide to each side, so that in summer the glass can be out of the way and allow the admission of plenty of air. Two round holes are cut for the admission of the fowls and are closed with sliding doors. In each end of the building near the roof there is left an opening for ventilation, to be closed in the same way. The house is divided into two rooms, each ro by 6 feet, with a lath partition and a battened door. The foundation of the house was made by digging a trench about a foot wide and deep, filling the same with stone and cement; upon this an eight inch wall, three tricks high, was laid. The foundation cost nine dollars. The floor is of earth and is filled inside the house nearly up to the sills, and outside sufficiently to form a good watershed. The following is the actual bill for materials and labor. The house was built by a carpenter, and the foundation laid by a mason.

Cost of foundation................... $\$ 9.00$

564 feet of matched pine @ 3 cents........... 16.92

52 “ spruce@. $018 \ldots \ldots \ldots \ldots \ldots \ldots \ldots \ldots .94$

58 “ chestnut $@ .025 \ldots \ldots \ldots \ldots \ldots \ldots \ldots . \ldots \ldots$

150 “ spruce @ .018............... 2.70

340 " hemlock @ .015............. 5.10

2 latches and handles.... $\ldots \ldots \ldots \ldots \ldots \ldots . . .20$

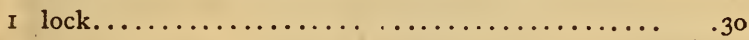

36 feet of moulding (under edges of roof)..... .90

20 lbs. of nails @ 4 cents................ .80 
53 lbs. of tarred paper @ $31 / 2$ cents.......... 1.86

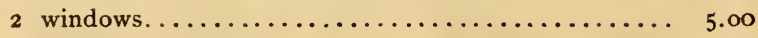

30 hours labor @ 30 cents................. 9.00

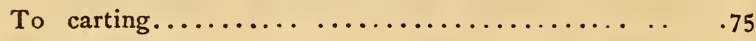

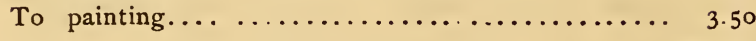

$\$ 58.42$

This furnishes an admirable house for one or two breeds. I use it for two breeding pens, there being kept in the house at the date of this writing twelve Leghorns and nine Dorkings.

The farmer or fancier who constructs his own house could of course save considerable on the above bill. $\mathrm{He}$ could lay a good stone foundation which would answer every purpose, and he could do his own carpenter work and painting. His savings would be something like this:

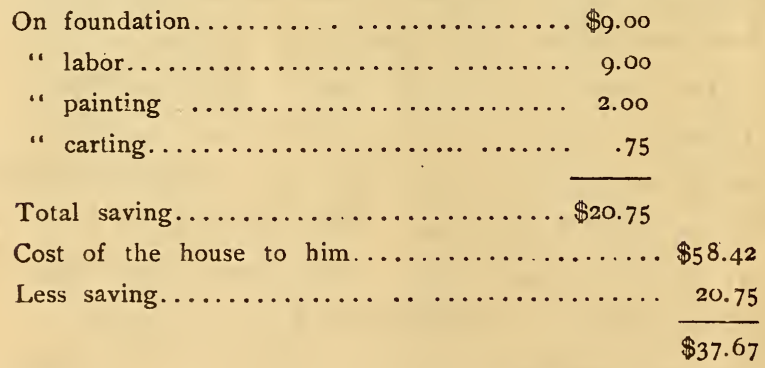

This is a small sum to expend for so good a poultry-house.

A cheaper poultry-house can be built by allowing the roof to extend almost to the ground, as in Fig. 4.

This cut needs little explanation. The advantage gained is obvious. This plan was suggested by $\mathrm{Mr}$. H. H. Stoddard, in his valuable little work on "Poultry Architecture," to which the reader is referred for numer- 


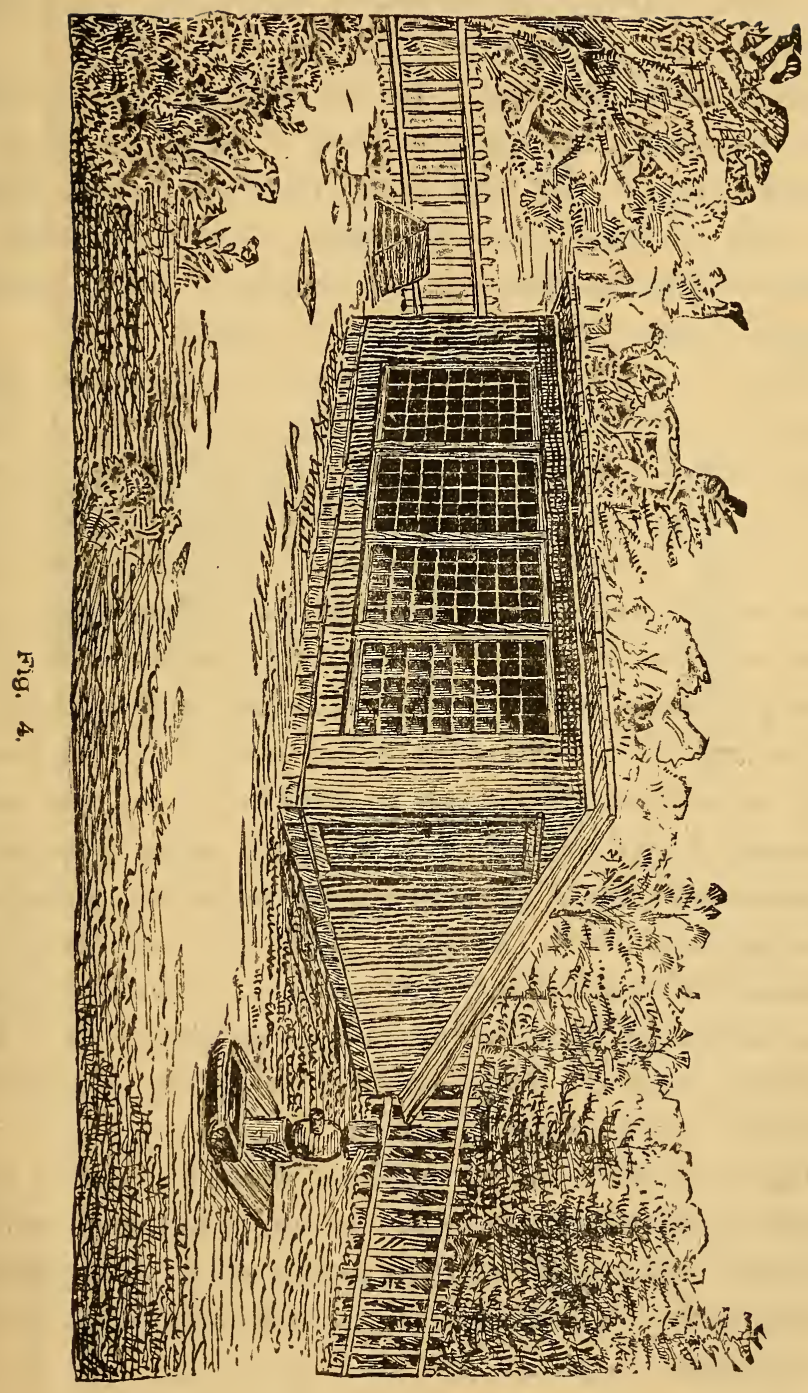


ous plans. This is an admirable house for the farmer to build.

Next comes the yard. If you keep but one variety, and can allow the fowls to run at large, no yard is needed. But if you have more than one breed, which you wish to keep from intermixing, you must build a yard, and the questions of size, height of fence, fencing materials, and other details must be settled.

Make your yard as large as you can afford to. The larger the yard, the better your fowls will thrive. A yard $20 \times 50$ feet will answer for a flock of twenty fowls, and you can keep that number in one-half the space, but they will not do so well if thus crowded. The height of your fence will depend upon the breed kept. Hamburgs, Leghorns and Games require a fence not less than six feet in height, while eight feet is still better. The Asiatics can be kept in a yard which would hold a pig. A fence made of one length of lath and pointed on top will keep Plymouth Rocks safely. You can build either permanent or movable fences. The latter possess some very decided advantages, as fresh soil for fowls is very desirable. Movable fences are built in the form of the old Virginia snake fence, by allowing the rails to project a little beyond the pickets. They can also be made in lengths as shown in the following figures.

Fig. 5 shows a length of fence with the posts. Fig. 6 shows a sharpened post, with the two hooks upon which the fence rails are hung. The length of the post should depend upon the character of the soil into which it is to be driven.

A very good permanent fence can be built by setting 
posts at the usual distance, providing light top and bottom rails, and nailing around the bottom next to the earth a board, above which laths sharpened at one end are used for pickets. This is an economical fence. The best fencing material is the galvanized wire netting, which can be procured of almost any desired width and at very reasonable rates. No fence rails are needed when wire netting is used, but a good, wide bottom board should always be provided.

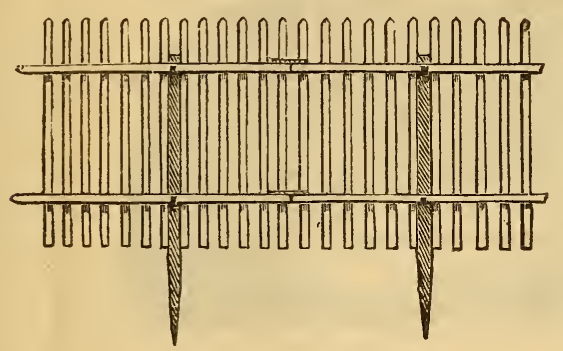

Fig. 5.

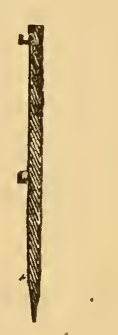

Fig. 6.

Chicken coops are made of all shapes and sizes, but for general use, expense being taken into consideration, nothing better than the old fashioned " $A$ " coop has been designed. It is well to have a floor inside to raise the chicks above the wet earth-an important matter when a cold storm is in progress. An A-shaped lath run in front of the coop, to enable the hen to get at the earth and into the sun, is desirable. It will be found convenient to have the bottom board of the back of the coop hung on hinges, so that the breeder can easily reach the hen and chicks whenever he wishes to do so.

A barrel laid down upon its side and propped up, so as to prevent water from standing in it in case of a 
driving storm, will answer very well for a coop, though it is not convenient to get at the hen or chickens when it is necessary to examine them.

Cat-proof, rat-proof, and crow-proof coops and runs are demanded in some places. They are not difficult to make, but fine-meshed wire enters into their construction. Fig. $7^{*}$ gives a very good idea of such a coop.

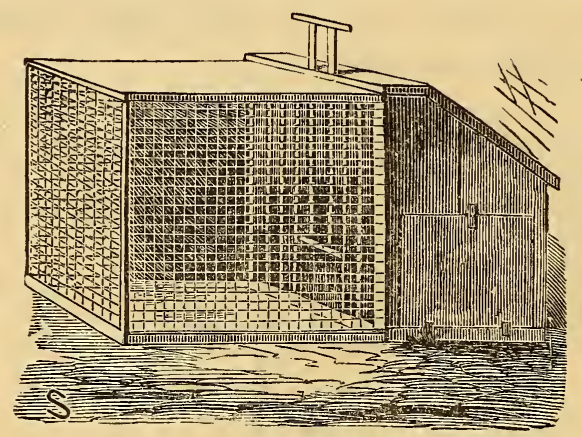

Fig. 7.

MATING.

We have now built our poultry-house and yards and purchased our fowls, and naturally desire to mate them so as to produce the best results. We have selected a breed, and wish to retain those characteristics which determined our choice. Upon what principles shall we make our matings to produce chickens which shall be equal or superior to their progenitors? If we make correct matings, we may feel reasonably sure of retaining the desirable characteristics of the breed, but if our fowls are incorrectly mated, their descendants will prove inferior to

* This design, as well as the one on movable fences, is borrowed from "Poultry Architecture," by. H. H. Stoddard. 
the old fowis, and the deterioration will have begun, which will, in time, render the descendants of the choicest specimens of thoroughbreds little better than the common dunghill fowl. This, then, is a very important matter; in it too great care cannot be exercised.

There are some general principles which ought to be stated:

I. Fowls matched for exhibition are seldom properly mated for breeding. Matching and mating are not the same thing. For this reason, oftentimes, a purchaser of the breeding pen which has just been awarded the first premium at some of the poultry exhibitions, looking for something admirable in their progeny, meets with bitter disappointment. The fowls did look finely together, but they were matched, not mated.

2. The best specimens of the breed ought to be saved for breeding purposes. Resist the temptation to dispose of your finest stock, no matter what the price offered, if you wish to succeed. I know the temptation is great, when one has received a liberal offer, to dispose of just those birds which he ought to retain. It seems like a loss to refuse the offer, but you will get your pay in the future, if you do; and you will, too, if you do not.

3. The deficiency of the hen must be met by a corresponding surplus in the cock, and vice versa. To illustrate what is meant-suppose you are breeding for a plump, round breast, and your hen is lacking in that quality, the cock with which she is mated ought to have a breast excessively prominent; so that the progeny; will reach an average which will meet your desires. 
4. Do not breed from immature stock. Pullets sometimes prove good breeders, but hens are generally much better. If your breeding stock is not fully developed, they will not be likely to throw as large or vigorous chickens, for, being not fully grown, their young will be likely to inherit only the size to which they have attained; and, not having matured, a portion of the forcewhich should go into the chick-is used in the development of its mother.

5. Breed from stock of different ages; or, in other words, mate young cocks with old hens, and old cocks with young hens. The very best mating, which you can make, is that of a cock a little over a year old with hens two or three years old. This gives size and vigor in the chicks. Next to that is the mating of a two-yearold cock with hens one year old, which have already laid one or two litters. Good results may be obtained from mating a two-year-old cock with hens of the same age, but from such a mating you will be apt to have fewer chicks, although those which you do get will be likely to be satisfactory.

6. Do not breed in-and-in. This, in time, will weaken the constitution of your chicks, until they become practically worthless. Yet it is better sometimes to breed in once, as, for example, to breed a cock with pullets of his own getting, than to obtain fresh blood from a strain whose characteristics are widely different from those of your own strain. It is sometimes very necessary to breed in, in this way, in order to fix some peculiarity; but you must remember, when you are doing it, that you are taking the first step toward degeneracy, and that 
death lies that way. This will lead you to carefully balance the advantages with the disadvantages, and you will not be likely to allow small advantages to lead you far into a course which is so fraught with danger.

7. The hen leaves the greatest impress upon her own chickens, but the cock leaves his impress upon the greatest number. If you are trying to reach the highest degree of excellence in a ferw chicks, the hen is of more importance than the cock; if you desire to obtain the highest average results, the cock is of the greater importance. According as your aim is will be your selection, if either the male or the female must be the inferior. The best rule is to have them both superior

8. Weight, easiness to fatten, rapidity of growth, fecundity, are all qualities which can be bred, as well as those outward qualities-the shape and size of combs, color of ear-lobes, and markings of plunage. The first are intrinsic, the second extrinsic qualities. If one class of qualities must be sacrificed, it is better that it be the latter, but with time and care both may be united. Prolificacy is no more intangible a quality in a hen than speed is in a horse, and we know in these days, when the seconds, which separate a horse's record from two minutes, are a constantly diminishing quantity, what blood and breeding will do in this respect; nor is it more intangible than the milk-giving or butter-producing qualities of a cow, and we are living in a day when breeding is demonstrating the ability to produce milk and butter in quantities which would have made our grandfathers think that the impossible had come to reign upon the earth. And so, too, with other valuable qualities. The only 
thing to make them certain in our fowls is to breed from strains which are noted in this particular direction. The fanciers of this country have been breeding too much for the merely external qualities. The temptation to do so is strong, because such qualities show; they win in the exhibition room, they gather in the prizes, they fill the eye of the purchasers, and make money for their owners. But the time is coming, even now the signs of promise are in the air, we can already see the first streaks of the dawn of that day which shall right all this wrong, and put the breeder of intrinsic above the breeder of extrinsic qualities alone. Breed, then, for intrinsic rather than extrinsic qualities, but unite the two, so far as possible, without any sacrifice of the former to the latter.

These general rules will be found applicable to all breeds of fowls. A few applications of these rules to mating poultry will convince the breeder of their importance. It will not be amiss to note some matings of those breeds which are well known, for in so doing we shall illustrate the principles which underlie almost all matings.

One of the most difficult breeds to properly mate is also one of the most popular of the Asiatics,

\section{PARTRIDGE COCHINS.}

To produce the best results, two matings are necessary; one for the production of cockerels, the other for the production of pullets. For the production of cockerels, the cock must be possessed of good symmetry; small, evenly-serrated comb; broad and beautiful saddle; 
full, abundant fluff; tail carried low and as free as possible from quill feathers; shanks, feet and middle toe well feathered; breast, fluff and leg feathering solid black; hackle, what the Standard calls fine orange-red, toward the front very dark; saddle, same color as hackle, with stripe of saddle and hackle feathers jet black. The hen should have a small head; a small and fine comb; hackle of a rich orange; ground color dark, handsome brown; broad, ample cushion; penciling of a deeper brown, very fine, nearly covering ground color upon breast and flat of wings; secondary quills very black; cushion almost black. Such a mating will produce fine cockerels.

For the production of pullets, the cock, while possessing all the Cochin characteristics, ought not to have a black fluff and breast, but a good proportion of brown or red therein, feathers laced with red better than solid brown or red; hackle and saddle bright orange, lighter than in cock mated to produce males. The hen should have bright orange head and hackle, the latter striped with solid black, although this is not absolutely necessary; ground color of body light brown; center of breast and flat of wings penciled with semi-circles of quite dark color; back well penciled; cushio. penciled so as to nearly cover ground color; and short secondary quill well penciled. Such a mating will give a good percentage of exhibition pullets.

Some of the best breeders of this variety claim that a fair percentage of standard cockerels and pullets can be obtained by mating together standard birds, and that, therefore, two matings are unnecessary. We think, however, that the two matings mentioned will be found to 
be more satisfactory in results than a single mating of standard birds. At least, such is the practice of the very best breeders.

BUFF COCHINS.

Do not use a bird of either sex with faded feathers, white tail, or of light weight.

The cock should be of a rather dark buff color, especially on the tail and wings; the rear half of back should be wide, with heavy saddle, rising dome-like to the stern; tail coverts chestnut; tail dark chestnut; thighs stout, rich buff color, the feathering extending down outside of shank and covering middle toe. The saddle and lower part of hackle covered with abundant, long-pointed, full buff plumage. Mealy appearance upon the wings is highly objectionable.

The hen should have small head, comb and wattles, short neck, rich buff color; full plumage in cushion, fluff and even to the feathering of the middle toe; tail almost invisible.

\section{WHITE COCHINS AND BLACK COCHINS}

follow the same general rules regarding mating, except as to color; and in all solid colored fowls to produce plumage it is only necessary to see that both cock and hen possess the right color, free from feathers of any other hue. White and Black Cochins should be mated, the hens and cocks both having the Cochin characteristics, and selected much as you would for the mating of Buff Cochins, except as to color. $\mathrm{He}$ who has learned how to mate Buff Cochins needs no instruction in mating White or Black Cochins. 
LIGHT BRAHMAS.

In mating this breed, if the male has a dark hackle, black wing-flights and black tail, he should be mated with females lighter in those points, and vice versa. For some unknown reason the sire-in this breed, at leastseems to have more influence on the plumage than the dam, so that if you have a good cock you are quite likely to get good plumaged chicks. The mating of pullets with a cock two years old is an admirable one, and produces very satisfactory results.

\section{DARK BRAHMAS.}

The mating of Dark Brahmas is not one-half so difficult as the obtaining of standard birds, for the best mating is the mating, of standard birds; that is, those of both sexes which are free from the faults enumerated in the Standard. Clear plumaged, large birds, the cock with clear black breast, and the hen with finely penciled plumage, free from brown shades or brown feathers, give the mating desired. It used to be considered necessary to make two matings of Dark Brahmas, and that practice is still followed by some breeders, but we think that the experience of the most eminent breeders will fully sustain the text, that one mating is sufficient.

\section{PLYMOUTH ROCKS.}

The Standard imposes a special hardship upon this noble breed by requiring the birds to match in the show pen, while Nature does everything to prevent such a result. The males will run light and the females dark under the treatment and handling of the most experi. enced breeder. Three matings may be madt. 
I. After rejecting all of the darkest pullets and all of the lightest cockerels, take of the remainder the darkest pullets and mate with one of the lightest cockerelsnot akin, of course. This will give light cockerels, a majority of the pullets the color of the mothers, and a few lighter pullets, which are very desirable for breeding purposes.

2. Take pullets lighter than those used in first mating and mate them with a medium colored cockerel. This is a good mating, especially for cockerels.

3. Mate the lightest pullets with a dark medium cockerel, but be careful that the cockerel is not too dark or you will get black pullets. If the pullets are quite light of course the cockerel can be almost of their shade and black chicks not result from the mating.

\section{HAMBURGS.}

In mating the different varieties of Hamburgs, it is necessary to see that both male and female have the true Hamburg shape and characteristics; if spangled, that the spangling be clear, the feathers well marked; if penciled, that the penciling be the same; and that the colors for cock and hen be such as are required in the American Standard of Excellence. Breed a large number, from which to select your exhibition birds, for with the most careful mating there will be not a few imperict specimens.

LEG HORNS.

To produce good combs in the cockerels-that is, combs which do not have a tendency to lop over-select 
a hen having a strong or even, upright comb; this will give good, firm, erect combs on the cockerels.

Mate hens with large combs, falling well over to side, with cockerels with medium size combs; this will give good pullets.

In other respects let your birds be good show birds, with the exception of the color of the ear-lobe, which should have a shade of yellow, instead of being white, as the Standard at this writing demands, and with the further exception in White Leghorn cocks of having a golden tinge to the plumage, especially of the hackle.

This yellow tinge in ear-lobes and in the plumage of White Leghorn cocks is the usual attendant of yellow legs and yellow skin, which make the fowls more desirable when they are marketed.

The Leghorns, in addition to their other good qualities, it will be seen, are easily mated, the natural mating throwing a good percentage of fine chicks.

A careful study of the general principles laid down for mating, and of the special examples given of mating certain breeds, will enable any one to mate almost any breed of fowls so as to produce fairly good results; but only a natural genius for mating stock, an eye which can, from a glance at the sire and the dam, see the figure and the markings of the future chick, will enable a man to achieve the highest success as a breeder. Instruction is valuable, rules are of service; but the breeder, like the poet, is borı, not made.

INCUBATION.

You have settled upon the principles of mating your 
flock, and have purchased the male bird, and now you ask, "How many females ought I to put with him?" If he is young and vigorous, he ought to have not less than six nor more than fifteen to secure the impregnation of the eggs; about a dozen is a good number. You can place more hens of the smaller breeds with the cock than you can of the larger, for the cocks of small breeds are more active and pay more attention to their flocks.

This question settled, you secure ten or twelve hens and put them into the yard with the cock. In a short time your ears are saluted with "cut, cut, cut-da-cut,cut, cut, cut-da-cut," and you go to the nest and find a new-laid egg.

The new-laid egg, how nicely turned!

How perfect it in every part!

Come, wise man, tell, with all you've learned,

From Science's laws and rules of Art,

What shapes the egg so perfectly ;

What wondrous hidden chemistry

Converts from corn, as by a spell,

The yolk and white within a shell.

There is much which science cannot explain, but we do know that an egg is composed of a yolk, surrounded by albumen or the white, and this wrapped in a thin membrane, and the whole enclosed in a shell, the principal component of which is lime. It is supposed that the yolk is composed of blood and a certain proportion of oil extracted from the grain which the hen has eaten. We need not be surprised at this, for chemistry has taught us that sugar is identical in its elements with the shirts on our backs, and a very good article of brandy 
can be made out of fence rails. The yolks or ova grow in a cluster on the spine, and pass through a fold of soft skin between the lungs and the kidneys. When the yolk is matured, it drops into the mouth of a funnelshaped duct, fifteen or twenty inches long, made up of three divisions, each one terminating in an elbow. The yolk makes three revolutions, in passing through the first of these divisions, and gathers to itself three layers of the white, in much the same way as a snowball gathers layers of snow when rolled over and over. The second division moves the partially formed egg forward with a rotary motion, thus giving it a finished shape, and adds the enclosing membrane. The third division completes the work by adding the shell, colored to suit the breed. The egg is fertilized by the influence of the male, which passes through a small duct along the spine to the clustering ova.

We have the egg now, but our curiosity is not satisfied, and we cry out,

Explain to me, if this you may,

How life lies hid within the shell;

How warmth shall bring some future day

This life to light, I pray thee tell.

Unfold, O, Sage, the mystery

Ensphered within an egg may be,

And teach me how from yolk and white

The downy chick is formed aright.

And the Sage replies, "The chick is formed entirely from the white, and here we see the use of the three revolutions, in the first division. The first layer forms the bone and sinew, the second the flesh, the third the 
skin and feathers. The first part formed is the eyes, appearing as two black specks, one on each side of the suspending cord at the large end; next the skull bone between them; and then the neck, spine, legs and wings in the order mentioned. In nine days there is a complete circulation and life has begun; in fourteen all the white has been wrought into the growing chick. The chords have become connected with the stomach and from the navel protrude in a number of blond vessels, enclosing the yolk in a net-work of finer ones. From this yolk the chicken is nourished, the yolk being reconverted to blood. The blood vessels gradually contract until the yolk is drawn into the chick, the navel closes, the shell is cracked, and the chick emerges."

"Ah!" but you say, "Mr. Sage, you have described some processes but you have not unfolded the mystery. The reason is still as obscure as it was in the begining."

"But I have given you," he answers, "all that Science knows or Philosophy teaches upon this subject."

Then you exclaim-

"Cease then thy vaunts, Philosophy,

To teach to man the laws of life;

What worth thy boasted formulæ,

Which have the ages set in strife.

If common things transcend thy ken

Daily observed by common men,

If when for knowledge we thus beg

Thou stumbleth blindly o'er an egg !"

We have anticipated a little, for, if ycu remember, your hen had just laid an egg. She will have to lay 
quite a number of them, and several weeks will elapse before she becomes broody (provided she does not belong to the non-sitting varieties, in which case your waiting would be in vain), and you can prepare for chickens. Incubation is an interesting process, and you may indulge your tastes in it in two kinds, natural and artificial. Naturdl incubation, of course, is where one makes use of the hen to hatch the chickens, and generally to bring them up. The first thing to be done, after you discover a hen giving infallible signs of a desire to sit, is to provide for her a suitable nest in a suitable place. The place should be secluded and where other hens cannot get to her, either to lay in the same nest or to quarrel with her over its possession, and to break a portion of the eggs in their struggles. If it be early in the season, make the nest in as warm and sheltered a place as possible, and of plenty of broken straw or hay, pressed down so as to make it slightly concave, just enough to keep the eggs from rolling out, but not concave enough to make them roll against each other, each one tending to the center of the nest. If it be a little later in the season, make your nest by cutting a sod of suitable size to fit the box or barrel in which the nest is to be made; invert the sod and hollow out the nest, and cover with a thin sprinkling of straw, hay or leaves. If you cannot conveniently get a sod, fill your box with earth from which the larger stones have been removed, and in this earth shape the nest as before described.

Remove your sitter to the nest at night, placing under her a number of nest eggs, until you are satisfied that she "means business;". . then you can remove the 
nest eggs and put under her a sitting of eggs for hatching. The number of eggs to be placed under a hen will depend upon three things - the size of the eggs, the size of the hen, and the time of year. I generally place twelve Plymouth Rock eggs under a Plymouth Rock hen-which breed, by the way, makes admirable sittersif I wish to set one in April; if later in the season, when the weather has become warmer, I add to the number, and make it fourteen or fifteen. Hens of this variety will cover and hatch even a greater number, but I prefer not to use more than about fifteen.

Twice or three times during the time that the hen is sitting, the last time about five or six days before she hatches, sprinkle her thoroughly with sulphur, to banish vermin from her and her chicks. I generally sprinkle upon the straw a small handful of smoking tobacco when I make the nest.

When the twenty-first day arrives be careful not to be too curious, or you may lose some chickens. Your hens ought to be tame enough to submit to handling, but it is generally well not to handle even tame hens at this critical period. Some advocate the removal of each chick as soon as hatched, until the hen has completed her hatching. Such a course will probably prevent her leaving her nest before completing her contract, if she is a tame hen; but if not, you may so frighten her as to cause her to desert her nest. If the chicks are removed, they must be supplied with artificial heat. It is not a bad course to pursue, and one which I believe pays quite as well as any, in the long run, to leave the hen entirely alone, and let her do her own hatching. 
Do not remove chicks from the shell. Except in very exceptional cases, the chick which cannot get out of its own shell unaided it is not worth while to attempt to rear. If you are very desirous to play the part of an accoucheur, the best thing will be to do it in the proper construction of the nest, proper precautions against vermin, and perhaps one or two sprinklings of the eggs with tepid water a day or two previous to the time of hatching. The do-nothing-at-birth course is one which takes the least of your time, and generally gives very good satisfaction.

Don't feed your chicks when first hatched. The remainder of the yolk, which they have drawn into them, will supply them with nourishment for the first twentyfour or thirty-six hours.

In about twenty-four hours after the hatching has begun, you can remove the hen and her brood to a" suitable coop 'with run attached, which you have already prepared. The subject of feeding the chicks will be treated of in its proper place.

It is a good plan to have two or more hens sitting at the same time; then you can remove the chicks from one and give them to the other to rear with her own, and can put another sitting of eggs under the hen you have robbed, making each hen, after the first one, hatch out two broods for you.

In artificial incubation you must supply the elements which make natural incubation successful. The failure to supply any one of these elements will render the result to be derived problematical, and may issue in partial or total failuire. These elements are heat, air and 
moisture. If these are supplied in the right amounts and at the right time incubation will be successful. The incubator, which complies with the natural requirements and furnishes at the proper time and in the proper amounts the natural elements, is the one which you wish to procure, if you desire to raise fowls artificially. Lẹt us defer for a moment the further consideration of this topic to inquire whether an incubator is needed at all.

If you do not desire to raise more than one hundred chickens and you wish to study economy, you will not purchase an incubator, unless you are anxious to obtain very early chicks. The expense of the incubator and brooder, and the time, trouble and expense of running them, ought not to be assumed unless for special reasons. But there are some very decided advantages to be gained by using an incubator.

Ist. You can hatch your chickens at any time in the year. This will enable you to get out early chickens, to be sent to market and sold at high prices, when broilers are about as rare as January strawberries. You can also get Asiatics, which require a long time to grow, out of the shell early enough to give them time to obtain their growth and make better specimens for the exhibition room. Where you rely upon hens for incubators, they sometimes show a strange reluctancy to sitting, until quite late in the season, and, on "the early bird" principle, your opportunity goes by, because your hens refuse to sit. A lover of chickens, rejected by an opinionated old hen!

2d. The chickens hatched in an incubator are free from vermin. A lousy hen ought not be allowed to 
sit, but if your nes: has been made as has been recommended and you have faithfully sprinkled her with sulphur, your chicks will be free from lice. The trouble is, many forget to do this, and the little ones are hatched out, and in a week or two begin to die, all because of that "lousy nuisance," a sitting hen.

3d. You can hatch out a large number at a time, so as to have many of the same age to select from, whereas if you had depended upon hens for incubation, you might have been obliged to wait a long time before you could have found a sufficient number of hens, which desired to sit at the same time, to accomplish your purpose.

$4^{\text {th. }}$ By using an incubator you can keep your hens laying and, from a small stock of finely bred hens, raise a much larger number of chicks than if you allowed them to sit.

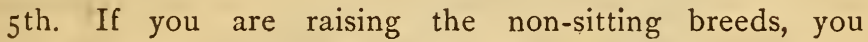
will be obliged either to keep some sitters, buy, borrow, beg or steal sitters of your neighbors when hatching time comes around, or rely upon your incubator. The latter is what you are quite likely to do.

These, and perhaps other advantages, have made the subject of artificial incubation popular, and have stimulated inventive genius to produce something which will successfully take the place of the sitting hen.

Observation of what the hen does, will teach us what an incubator ought to do. In the first place we find that a hen sits steadily, seldom leaving her nest, for the first four or five days. By placing a thermometer under her we find that her heat is about ro3 degrees. 
In an incubator we should observe the same conditions, furnishing a steady heat of about 103 degrees without disturbing the eggs.

A hen by constant sitting becomes somewhat weakened; her natural temperature drops down a degree or two; she leaves her nest and daily turns her eggs. This we should imitate in our incubator, airing the eggs and turning them as that natural incubator, the hen, does.

And, again, we know from a certain scientific law, that even when the hen cannot get to the grass in the morning when the dew is on it, she imparts, from her own vital tissues, moisture to the eggs. If we could measure the exact amount and could know just the times when this moisture was given to the eggs, we could tell just how much should be supplied in artificial incubation. We know that the incubator must supply some, and carefully conducted experiments ought to teach us how much. Here is a field for the experimental scientist, which will pay for cultivation, for he, who can give a perfect incubator, will be able to control the market, and the market will be a large one.

As soon as your chicks are hatched, they should be removed to the brooder or artificial mother. Many manufacturers of incubators also make brooders to go with them. As in the incubator the processes of the hen were imitated, so in the brooder you should copy from this pattern. Warmth from above should be shed upon these now motherless chicks, like that from the brooding wings of their natural mother. Ventilation should be provided, so that the warm air is also pure air, and, with the proper supply of food and water, your chicks 
will be likely to do well. Indeed, so well do chicks raised under artificial mothers grow, that many people, who hatch the chicks with hens, prefer to raise them in brooders. As the brooder is much simpler in construction than the incubator, we extract from "Incubation; Natural and Artificial," by H. H. Stoddard, the description of one which can be made cheaply and easily, and has proved effective. The drawing and description were sent to Mr. Stoddard by Rev. Hugh Smythe, of Elizabeth, N. J., whose words we quote:

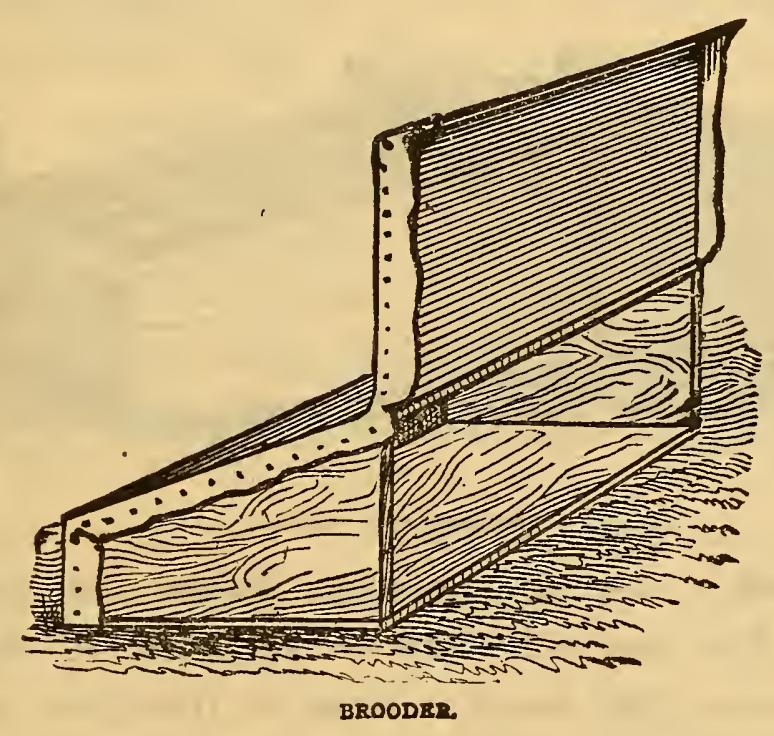

"The sash is the only part which everybody may not be able to construct at home. It consists of a common garden frame, which I easily put together myself (the sash cost $\$ 2.50$ already glazed and painted), and a slanting brooder fitted to the back or higher end. The brooder proper is made with a board floor, and ends, and covered with tin. This is made to slant back, as represented in the drawing, to about four or five inches 
at the back. The front is open to the run inside the frame under the glass. The tin is turned over at the ends and tacked fast. It is also continued up above the level of the glass and turned over to shed the water. Stakes are driven into the ground eight or ten inches back from the brooder, and rough boards are fitted to them, and the whole is then filled in with fresh stable manure closely packed down. The tin keeps the inside of brooder free from damp and smell. It should

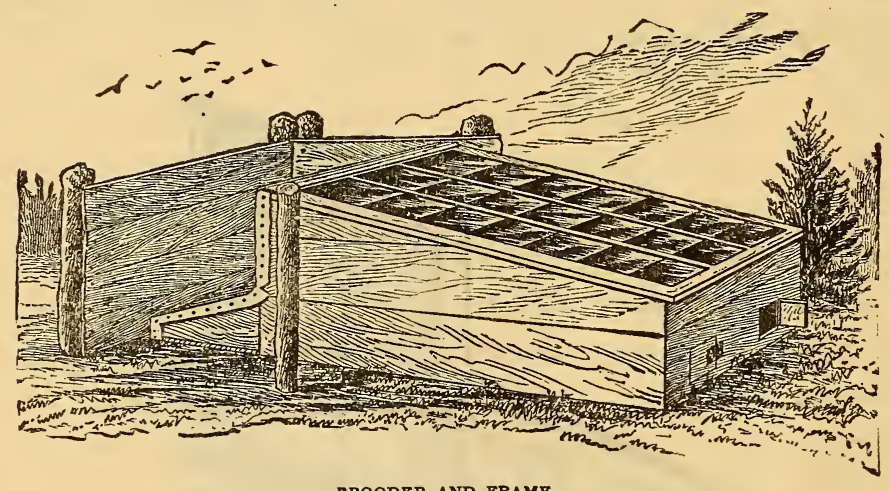

BROODER AND FRAME.

be prepared a day or two days before the chicks are put in. The heat will then be as much as they need, or can bear. The holes in front of frame are sometimes sufficient ventilation, but the sash may either be drawn down an inch or two or raised in front by a piece of wood, if more air is needed."

In most of the brooders heat is furnished by a lamp, as it is in the incubator. The one which we have described is said by its inventor to have been used "with exceptional success."

Many claim that bottom heat in a brooder is better 
than that supplied from above. Some breeders have certainly had excellent success with brooders heated from the bottom. A combination of top and bottom heat we think might be an improvement upon either.

\section{THE CARE OF THE YOUNG CHICK.}

Childhood has ever been a fruitful theme for author and poet; its joys, its sorrows, its hopes, its aspirations, its successes and its failures we all look back to, and distance, in time as well as in space, "lends enchantment to the view." But the sober statistician looks upon childhood in a very different way. To him it is a period of numerous ailments and great mortality. Our view of the childhood of a chicken, or the chickenhood of a fowl, resembles more that of the statistician than that of the poet. Tender days they are to be sure, but tender physically rather than sentimentally. A. chicken is often but a frail flower, to-day it is, to-morrow it is gone. Lice sap its vitality or the gape-worm does its fatal work; diarrhœa exhausts its strength, or constipation kindles a fever in its blood; the scorching sun burns out its little life, or the merciless rain extinguishes its feeble light; the careless feet of its mother trample it to death, or the exposed pail of water becomes its grave; while rats, cats, skunks, hawks, crows and owls render the days terrible and the nights full of horror. Despite them all, however, with proper care and wise precautions the greater proportion of the chicks hatched may be reared to a useful maturity.

If we bring up our chicks under a hen, as the most of us undoubtedly do, we remove the hen and her 
brood from the nest where the chicks were hatched to a suitable coop with a lath run in front, when the chicks are about twenty-four hours old. For the first few days the chick's food consists of the yolk of a hard boiled egg, chopped very fine and mixed with bread crumbs. Milk, if we have it, and if not, good, fresh, clean water, is furnished for drink. This diet is continued for three or four days, and five meals a day are furnished. In the course of two or three weeks the number of meals per day can safely be reduced to three. A continued diet of eggs and bread crumbs is not only expensive, but leads to constipation. The egg food, however, may be continued for an indefinite length of time, to the advantage of the chick, if given but once a day. When the chicks are three or four days old, you can feed them with Indian corn meal, mixed with boiling water, which cooks the meal and makes a hasty pudding of it. A still better way to cook the meal is to wet it up very thin and watery and then put into a hot oven and allow it to bake. The water swells the meal, and the heat cooks and dries it. Indian meal, however prepared, should only be fed to chicks when in a crumbly state. If you continue the egg-diet, chop the white and yolk and shell together and feed once a day or once in two days. Wheat bran and oat meal, mixed with corn meal, also make a good food. When the eggdiet is discontinued, and we recommend that it be not wholly discontinued until your chicks are six or eight weeks old, if you are striving to raise extra fine ones, animal food in some form should be supplied; and this is especially necessary if your chicks are closely confined. 
When they run at large and have a free range, the numberless bugs, grasshoppers and worms which they obtain satisfy the carnal cravings of their appetites; but in confinement they cannot get these things and their keeper must furnish the bugs, grasshoppers and worms or a satisfactory substitute therefor. Cooked meat chopped fine will answer, the purpose. Boiled plucks and livers or any coarse and inexpensive meat is what should be provided, or the breeder can go into the business of raising maggots or meal worms. It is not an attractive business and yet a good maggot pit is not to be despised. To make one, dig a hole one foot to eighteen inches deep, fill with straw and horse manure, with a sprinkling of yeast and some mashed potatoes and corn meal, covering the mixture with about one inch of earth. As a single fly is said to lay five hundred millions of eggs in a season, each egg producing a maggot in nine days, it will be seen. that you do not require a great supply of flies. If we could only engraft the laying qualities of a fly on the hen we should deserve well of our own and future generations. A piece of meat buried slightly or hung up in the sun will produce many maggots. To breed meal worms it is necessary to get a supply, say a couple of hundred, (most bird stores have them for sale and bakeries have them sub rosa), and put them into an earthen jar, with scraps of leather, bran and damaged meal. Place cotton waste on the mass and keep it moist with water. The worms breed very rapidly and sixty days time will give you a supply for daily feeding. Green food must not be forgotten. Tender blades of grass, onions and cabbages, young oats, chopped fine, 
will be relished and will help to keep your young broods in health and promote a rapid growth.

As soon as the chicks get large enough to eat grain it should be furnished them. Cracked corn and wheat make a good food, and chicks will begin to eat such food when they are quite young.

Bone meal, or bone cracked fine enough for them to swallow, powdered charcoal, lime, sulphur, sand and gravel should be among the poulterer's supplies and should be frequently furnished to the growing broods.

Chicks don't always know enough to go in when it rains; therefore, you must keep them in when it rains until they are some weeks old. Keep them, also, from tramping through the grass when the dew is on it. Moisture, applied externally, to the young chick is deadly. Keep them from it and they ought to do well.

Incubator chicks need the same kind of care. They must be kept dry and warm, and their brooder kept scrupulously clean, and the air which they breathe kept fresh and pure, and they will thrive and grow rapidly.

\section{FEEDING FOWLS.}

Feeding, like any other subject, may have its philosophy, that is, its general principles, which underlie and explain the particular facts. These are not numerous; indeed, six principles will be found sufficient to explain the subject satisfactorily. These are-

ist. Feed for what you wish to produce. One system of feeding is best adapted to the production of eggs; another to the growth of flesh and fat; and another to the development of virility and the strengthening of the reproductive organs. 
2d. Feed according to the age of fowls. Fowls of different ages require different feeding. A babe needs milk, a strong man meat. Your chicks need one kind of food, your adult. fowls another.

3d. Feed according to surrounding circumstances. Fowls kept in close confinement depend wholly upon what is supplied to them. Fowls which have an extended range can find no small part of their living themselves. The first require obviously a different system of feeding from the second.

4th. Furnish a variety of food. "Variety is the spice of life," says the old aphorism; it is certainly necessary for the welfare of every living organism. It is not only agreeable to the palate, but is absolutely essential to keep the flame of life burning. A fowl has varied wants; it has to produce from its food bones, muscles, fat, feathers, and the constituents of eggs. No one food has been discovered which contains all the needed elements in sufficient quantities.

5th. Cleanliness in feeding is necessary. "Cleanliness is next to godliness," and you cannot afford to neglect it in feeding. If you do, the health of your flock will be likely to suffer, and loss ensue therefrom.

6th. Avoid overfeeding and underfeeding. They are the Scylla and Charybdis of the poultry raiser. The first produces disease, the second undermines the foundations of life. Feed what your fowls need, and no more. Avoid these rocks, (which are laid down upon the chart, but so indefinitely, that only the experienced mariner knows just where they are), avoid these dangerous rocks, unless you wish to make shipwreck of your enterprise. 
FEEDING FOR LAYING.

Feed only a small amount of Indian corn, as it possesses too much fat-producing material to be profitable, and a fat hen will not lay as well as one in good condition-neither poor nor fat. Plenty of food must be supplied or the hen cannot produce the eggs; a factory cannot run without a supply of raw material. A good system of feeding for laying hens is as follows :

In the morning give such soft food as you intend to feed, the scraps from the house, mashed potatoes mixed with a small quantity of corn meal and wheat bran.

At noon oats scattered over the ground, (in winter among straw or chaff to make the hen take exercise).

At night about equal parts of whole corn and wheat, or wheat alone.

Green food must be provided. Chopped cabbage and onions are excellent. Animal food also should be furnished twice .a week.

A feeding of oats fried in fat, once or twice a week, especially in winter, will be found profitable.

Lime in some form, (pounded oyster shells unburned is the best), must be provided for egg-shell material.

Milk is an admirable food for fowls. The more you use it the better you will like it.

Condiments, such as egg-foods, cayenne pepper, etc., may be given sparingly. Too much will cause the production of soft-shelled eggs.

FEEDING BREEDING STOCK.

The problem here is not so much how to increase the number of eggs as how can the most vigorous chick- 
ens be produced. Vigorous parents, on the principle that "like produces like," ought to produce vigorous children; but we know that, however fine our stock may be when purchased, we may, by a wrong system of feeding, destroy its vitality, and the young which spring from it will be "degenerate scions of a noble stock." One fact should be remembered, or rather one law should be stated-the young is affected by the condition of the parents at the exact moment when begotten. Drunken parents, in a maudlin condition, have begotten. idiotic children. Parents, in a low state of health, have begotten children with impaired constitutions. Fowls out of condition produce chicks out of condition, which do not live out half their days, and live that half in a state of weakness and uselessness which makes you, when the end finally comes, wish that they had "died before they were born."

Feed your breeding stock so as to keep them in vigorous health. Let their diet be generous but not stimulating. Plenty of oats, and wheat, little corn (for we do not wish to produce fat but muscles), plenty of green food and clean water, with now and then a taste of meat to keep them in heart, and furnish a varietythis is the diet which leads to chicks that do not die in the shell, or hold on for a few days after hatching to the slender thread of their existence, only to snap it in twain with the first noticeable variation in the temperature.

FATTENING.

Rich food and plenty of it, close confinement and 
little or no exercise, now are demanded. Separate the sexes, putting the cocks into one pen, the pullets into another. Be careful to put together only such fowls as are accustomed to run in company, to prevent quarreling. Peace must reign or fat will not be a willing subject. Have your place so warm that some of the food which the fowl eats need not go as fuel to warm its quarters. This does not mean that the place should be hot. Let the place be dry, and for a part of the time, at least, dark. Corn meal, milk, buckwheat, barley, and a few potatoes are the staple articles of food, which should be cooked and fed warm.

There are two systems of artificial fattening, called cramming, in vogue in France and elsewhere - solid and liquid. The fowls are shut up separately in coops eight inches wide, the sexes kept apart, fowls of the same degree of fatness kept near each other, and everything kept scrupulously clean.

In solid cramming the food is made into rolls about two inches long, which, after soaking in milk or water, are thrust down the throat.

In liquid cramming the food is mixed to a semi-fluid consistence, and is put down the throats of the fowls by the aid of a funnel.

Elaborate machines have been invented for carrying into effect both solid and liquid cramming, and these systems are practiced largely abroad, and to some extent in this country. For profit, large establishments are necessary, and the reader who wishes to adopt either system of cramming is advised to consult works specially treating of this subject. 
DISEASES AND THEIR REMEDIES.

Print in large letters and nail up in a conspicuous place in your poultry-house "AN OUNCE OF PREVENTION IS WORTH A TON OF CURE." We have taken the liberty to alter the familiar aphorism by substituting the word "ton" for "pound," the latter word not giving emphasis enough. Diseases, even of fowls, can sometimes be cured, but it is cheaper, and more satisfactory, to prevent them. Under your motto print the following maxims:

r. Don't overcrowd your hen-house.

2. Keep your buildings well ventilated.

3. Keep everything clean.

4. Whitewash is cheaper than cholera, and fumigation more profitable than lice.

5. Sunlight is as necessary as corn.

6. Don't underfeed or overfeed, and don't forget that fresh water is abundant and cheap.

But even when all precautions are taken to ward off disease, it will sometimes appear. "Accidents will happen in the best regulated families." It becomes necessary therefore to know something about the diseases to which poultry is subject and the remedies by means of which they may be conquered.

Roup-Symptoms. A catarrh or cold in the head; dry cough and dull wheezing; much fever, the fowl drinking eagerly; comb and wattles either pale or dark colored; yellowish discharge, thin and watery at first, but growing thicker and thicker, from throat, nostrils and eyes; eyes and face sometimes greatly swollen; pustules about the head and in the gullet which discharge a 
frothy pus; crop generally swollen; the discharge has a bad odor and this is one of the distinctive symptoms.

Look under the bird's wing and see if there is not a spot where the feathers are smeared with the discharge from the beak; examine the nostrils; at night listen for rattling or wheezing among your birds.

Ticutment. Cut off the fowl's head in a severe case. This is the only known remedy which has never failed. If you are not equal to such heroic treatment, separate the sick bird from the others, as the disease is contagious. Give warm, stimulating food, and house in a warm, dry place. '.....e German Roup Pills are highly recommended. Give stimulants; mustard or pulverized ginger in pills as large as a pea thrice daily; cayenne pepper in food and drink which may be seasoned as strongly as you would use it for yourself.

Wash the eyes thoroughly with castile soap suds or with Labarraque's Solution of Chlorinated Soda, mixed with two parts of water, several times a day. If the throat be clogged with the secretion, clear it out and use the Chl. Sod. here, applying with camel's hair brusi.

Sometimes it is necessary to remove a cheesy lump under the eyes by an operation with the knife, but generally bathing will accomplish all that is necessary.

Pulverized sulphur blown through a goose quill into the throat and nostrils and other parts affected will be beneficial. This treatment has been tried in diphtheria and with good results, and roup resembles diphtheria very closely.

Bronchitis, Coughs, etc. Put the fowl in a dry place; keep it warm and give sweetened water slightly soured 
with sulphuric and nitric acid. Cayenne pepper or gingar in the food may hasten the recovery. Examine the fowl to see if the cough is not due to parasites in the air passages, as in the case of gapes in chickens.

Gapes-Symptoms. The fowl in breathing stretches up its neck and gasps; it sneezes and makes vain efforts to swallow; it has the general symptoms of not being in good health, such as lack of activity, moping about, dropping its wings, etc.

Treatment. Put some carbolic acid, of the clear, transparent quality, into a spoon or metal saucer and hold it over a lamp. Dense white fumes will arise. In these hold the chicken's head until it is nearly suffocated.

Another method is to take a feather, stripped of all the web save at its tip, dip it into turpentine or kerosene, and thrust into the wind-pipe and turn it around several times. Some of the worms will be killed, some will come out with the feather, and some will be coughed out. Burn them all.

Still another method is to confine the chicks affected in a small box over which is stretched a cover of thin muslin. Sift fine lime through this cover but not so fast as to smother the chicks. This will cause a violent sneezing and coughing which will expel the gape worms.

Cholera-Symptoms. The discharges are at first yellowish green, "like sulphur and water," becoming thinner, greener and more frothy as the disease progresses. The breathing becomes heavy and fast, crop fills with mucus and wind, the food is not digested, the eyes close and the fowl dies. These symptoms are accompanied by 
weakness, much fever, great thirst and a rapid, weak pulse.

Treatment. Separate the sick from the well, and, if you can do it, give every sick fowl a separate place. Remove the whole flock to new quarters. If you cannot do this, let there be a general house cleaning, whitewashing, fresh earth, nests oiled, vermin killed, house fumigated, runs spaded.

Dr. Dickie in an article recommends the following treatment: "Fowls that are too sick to eat should have every four or five hours a pill made as follows: Blue mass 60 grains, pulverized camphor 25 grains, cayenne pepper 30 grains, pulverized rhubarb 48 grains, laudanum 60 drops; mix and make into 20 pills. When they have had time to act, give half a teaspoonful of castor oil and ten drops of laudanum to each. Let them drink scalded sour milk, with a gill of Douglass' Mixture (see below) for every twenty-five head, a day. The treatment ought to change the character of the evacuations and make them darker and more solid. When this happens, and not before, give them alum water or strong white oak bark tea to drink, and no other drink."

The following treatment has been tried with success: Mix corn meal and wheat bran together, add cayenne pepper, and enough kerosene oil to go through the whole mass. Mix in proportions of about two heaping tablespoonfuls of pepper and one pint of kerosene to two pails full of the mixed meal and bran; add boiling water and stir thoroughly. Those fowls which do not eat must be crammed with this food. Put cayenne pepper and tincture of iron alternately into their drinking 
water. Follow up this treatment for three days if necessary.

Tonics and alteratives may be tried in the feed; iron, sulphur, cayenne pepper, soda, in succession. German Roup Pills are recommended on account of their tonic properties.

Indigestion-Symptoms. Either constipation or diarrhœa; fever, loss of appetite, sickly yellowish look about the head and comb.

Treatment. Five grains of rhubarb, changed every fourth day for one grain of calomel, is recommended by Wright. Cut down the diet to a little soft, bland food; limit the water supply and give cut green grass.

Diarrhea and Dysentery-Symptoms. Symptoms are too generally known to 'require specific enumeration; when accompanied with bloody evacuations the disease is called dysentery.

Treatment. For diarrhœa give six drops of camphorated spirit on barley meal. Restrict the drink and put a little tincture of iron or alum into it. For dysentery give a dose of castor oil, and follow with laudanum, five drops every few hours.

\section{PARASITES.}

Worms-Symptoms. General loss of health, but the only reliable symptom is finding them in the evacuations.

Treatment. Improve the general health. A dose of castor oil, followed by sulphur in the food, may be effcacious.

Scaly Leg-Symptoms. Grayish-white swellings on the legs, which may ulcerate. This is a species of itch, caused by a parasite, and is contagious. 
Treatmeni. Wash the legs thoroughly with castile soap and water, and apply sulphur and lard, working it under the scales. Stoddard's Poultry Ointment is convenient and reliable.

Lice-Symptoms. General appearance of loss of health. Examine the heads, under the wings, and about the anus. You will be likely to find them.

Treatment. Ist, of the fowls: Persian Insect Powder, powdered sulphur, carbolic powder and snuff may be blown or worked into the plumage. An ointment of sulphur, lard and kerosene may be applied to adult fowls, but beware of applying it to chicks. I once gave a thorough application of sulphur and lard to some White Leghorn chicks about a month old, and every one of them died within three or four days.

$2 \mathrm{~d}$, of the houses, etc.: Remove the straw of the nests, apply kerosene thoroughly to every spot which could harbor a louse; be thorough, and you will remove the evil.

Red Mites. Treatment similar to the above; be thorough.

These are some of the more common and more troublesome diseases which affect poultry. You will find these and others, with their remedies, more thoroughly discussed in "Poultry Diseases," by H. H. Stoddard, a little, work which every poultryman ought to possess. We close this branch of our subject with

\section{A FEW USEFUL RECIPES.}

Douglass' Mixture. Copperas, one pound, dissolved in two gallons of water; then add, stirring weil, one ounce 
of oil of vitriol; keep in jugs. This is a good tonic, in the dose of an ounce to a gallon of drinking water, twice or four times a week.

Chicken Powders. Four ounces each of copperas, ${ }^{\circ}$ cayenne, sulphur and resin; powder all; mix; two spoonfuls for each dozen fowls several times a week. A good tonic.

Lime Water. Four ounces of lime; one gallon of water; slack the lime with a little of the water and pour on the rest; cover and set aside for three hours; then pour off the clear liquid.

Tonics and Stomachics. A few drops of tincture of iron in the drinking water, or half dozen rusty nails thrown in the bottom of the vessel.

Cayenne pepper and asafœtida are good digestive stimulants; garlic and onions have a good effect on the lungs and bronchia; charcoal is a good purifier of the digestivé organs.

\section{THE EXHIBITION ROOM.}

The way to win prizes on poultry is to deserve them. Accurate knowledge of the various characteristics of your special breed or breeds, of the requirements of the American Standard of Excellence, and of the principles of correct mating, is absolutely essential. "The early bird catches the worm," and the early chick catches the first prize. Prize chickens must be hatched early; if of the larger breeds not later than April, while March is preferable. And they must be so reared as not to have their growth retarded by the cold weather. They must not know that this is a cold, cold world into which 
they have come. They must be reared carefully and be kept growing, for weight counts with all breeds except Bantams. With these you must reverse the process and get them out late.

When your fowls are well grown, you ought to select those destined for the exhibition room from the others. There will be but a small percentage found suitable. You must be very rigid in your selection, examining each fowl in detail, commencing with the comb and finishing with the toes in order, and rejecting every bird which shows any imperfection. Among these rejected birds will be many excellent breeding fowls, perhaps for this purpose equally or more valuable than the ones selected for exhibition, but they are not for the poultry show.

The few, which have stood the tests of your examination, are now to be fed for the show. For their morning meal give them warm cooked meal-and-potato mash; at noon, cracked corn, whole wheat and occasionally buckwheat; at night, whole corn, with crushed bone; and about twice a week broken scraps. Two or three times a week a meal of cooked meat will be useful. Give them only what they will eat up clean. Give them plenty of clean water.

About six weeks previous to the exhibition, at which you propose to show your fowls, these selected fowls must undergo another examination and selection. Out of them we choose the one or two pairs or trios that we intend to exhibit. These birds must not only be fine birds but the principles of matching (we are speaking of poultry shows as they are, not as they ought to be) must be understood now, for your pair or trio or 
breeding pen must "match in the show-pen" or they will be disqualified, no matter how fine each bird may be by itself.

The cocks now must be kept by themselves, and the pullets also by themselves in order to keep the plumage perfect. They must be well fed, not gorged but given all they will eat up clean, regularly three times a day. Rice boiled in milk is excellent for one meal. Whole wheat cooked in this way is also good. Boiled potatoes, mashed with either of these grains, is perhaps the very best food for one meal a day that can be given.

Give a small quantity of sunflower seeds daily to increase gloss of plumage. Feed meat sparingly.

If you have white or light-colored fowls wash them from twelve to twenty hours before shipping. Take an ordinary wash-tub, fill the tub with warm water (not hot) so as to cover the back of the bird; use pure white soap; rub the bird well with the soap on all parts that appear soiled; rub the feathers hard but do not break them. When you have thoroughly washed the bird, rinse him in another tub of cold water, previously provided. After draining put the bird into a clean coop and place in a warm room to dry.

For dull combs a good rubbing with brandy is recommended to restore their brightness. Ear-lobes of a yellow shade may be made over into a winning white by touching them up with whiskey; turpentine is also used for this purpose.

Cages are generally provided by the societies, but if you must provide your own cage paint on the inside, for white bodied birds, a dark green or brown; for dark- 
colored birds. a pure white. The birds show off better against such a back-ground.

In preparing your fowls for transportation cover the coops with coarse bagging or thick cotton canvas, on four sides. If they must be several days en route a sheet of coarse paper tacked on four sides of the coop may prevent frozen combs or wattles, leaving space for air.

Our poultry exhibitions ought to be reformed in some particulars.

First. The judge ought to have no means of knowing the ownership of fowls; and any exhibitor, who, by means of cards tacked upon the coop or by giving notice personally or by some agent, discloses the ownership of his or any other person's fowls, on exhibition, ought to be disqualified from competing at this show and for some definite length of time, say one or two years.

Second. Fowls ought to be scored individually and prizes awarded to the best individuals, not to the best combination. "Every tub should stand on its own bottom." A 95 point cockerel ought not to be spoiled by an 80 point pullet; nor a 97 point pullet by an 85 point cockerel.

Third. Prizes for breeding pens should be given to those pens mated to obtain the best results, not, as they now are, to the pens which have the highest aggregate score. Such pens might be denominated exhibition pens, but to call them breeding pens is a misnomer.

After the exhibition is over, have your fowls shi $d$ home, taking every precaution against colds. Give them as comfortable quarters as possible, giving them light and non-fattening food. You are anxious not only to get 
them into shape for breeding, perhaps, but also to get them into a natural state of health. A good diet for a month will be cooked bran and turnips mashed in the morning and oats and barley only for dry food. Plenty of bone, shell, gravel, and such other substances should be supplied. Chopped hay, cut short, may be given plentifully; cooked meat and boiled fish occasionally. Those that have colds should be treated carefully for them.

With good fowls, mated, reared, selected, matched, prepared, shipped, returned and restored in the manner above related, you ought to have won enough prizes and made a good enough record to satisfy any reasonable man, and to lay a solid foundation for patronage for the ensuing year. You have tasted trouble, you are now to enjoy for a time the sweets of success, and to make preparations for another and still more successful campaign.

POULTRY ON A LARGE SCALE.

The many will raise poultry in small numbers; but a few will be found who desire to engage in the business on an extensive scale. To a lover of fowls the business is an attractive one, and properly managed it is a profitable one. Within the remaining limits of this treatise it will only be possible to outline some of the more general principles that are involved in the undertaking; to state briefly the plans which some have proposed and tried, and to refer the reader to other sources of information where the subject is treated in extenso.

One of the first difficulties that is to be met is that 
large flocks do not do well, and that therefore the fowls must be separated into small flocks and scattered over the grounds. This can be done in three ways:

I. By building a large fowl-house and having runs close to each other, extending out in different directions. The fowls are under one roof, and the attendant can care for them more easily, having to traverse less ground in taking care of them. The objection to this plan is that the fowls are brought together in so large numbers that, although they are separated into small flocks, they do not do well.

2. The fowls may have separate houses with runs attached, each house containing but one small flock, and the houses well apart. The objection to this is the amount of the original outlay.

3. This is the plan advocated by H. H. Stoddard in his Egg Farm, a monograph upon this topic. His plan is to have the houses separated, painted different colors, so that the fowls can readily distinguish their own, and making "the mutual antagonisms of neighboring flocks take the place of yard fences, just as among wild jungle fowls." The advantages of this plan are the greater economy and the less outlay required.

The person who attempts raising poultry on a large scale must make that his business and manage it upon business principles. His problem is the production of marketable eggs, or marketable poultry, or both, at prices which leave a good margin for profit. $\mathrm{He}$ does not care for fine points in plumage, exact markings, perfect combs, ear-lobes of the precise standard shade, wattles rounded to a hair's breadth. All these he leaves to the breeder 
of fancy poultry. He says: "What I wish are fowls that pay, fowls that produce eggs in abundance, and make poultry on a small amount of grain. The purchaser of my eggs is not going to inquire whether the plumage of my fowls is nicely penciled, barred or spangled, but whether the eggs are fresh; and the purchaser of my dressed poultry does not ask whether the ear-lobes were perfect, or the comb had just five points, but he wishes to know whether the meat is juicy and tender." So he does not need to be particular about keeping his fowls absolutely pure in blood. A little intermixture of blood sometimes seems to him an advantage.

A poultry farm should be located near a city, in order to insure a good, market. This is especially important when eggs are the staple product. Eggs can be delivered weekly to families, in the same manner that milk is delivered, and with this advantage in favor of the eggs-that the route need not be traversed daily.

Soil capable of cultivation should be selected. Such soil furnishes a good market for the manure, which can thus be utilized to the best advantage. Our political economists of the protectionist school are loud in the advocacy of "a home market." Here is one to which the most rabid free-trader, would not object, but would be willing to admit that it was better than the best foreign market. It will be well to grow such crops as are most needed for home consumption; here, too, we are protectionists.

The buildings should be economical, both in construction and in convenience, saving of money and time. The breed of fowls will depend somewhat upon the 
object which we propose. If it be the raising of eggs as chief, with the disposition of only the surplus stock and extra cockerels as subordinate cnds, then White Leghorns or Brown Leghorns will probably be selected. If we desire to add to eggs the disposition of surplus stock, and to the disposition of surplus stock, the rearing of marketable poultry, we shall keep Plymouth Rocks or Dorkings. If we keep Leghorns, we may find it to our advantage to keep a few flocks of Light Brahmas for winter laying. These crossed with the common white fowls make good looking and very serviceable sitters; if we hatch out our chicks naturally we shall need them. The great improvements made in incubators and brooders in the past ten years may induce people to use artificial in preference to natural incubation, but we are so conservative that we confess to a prejudice in favor of "the good old way."

Numberless details attach to every important business, and poultry on a large scale is no exception to the general rule. Before engaging in it you will be wise to inform yourself of the requisites to success, the proper construction and location of buildings, the proper management and care of fowls, the labor-saving appliances which may be brought into requisition, the crops which should be raised on the farm, and the thousand and one things necessary to be known for the proper prosecution of such an undertaking. By all means read what has been written upon this subject, commencing with Stoddard's An E Erg Farm; but do not rest in simply reading. Seek out those poultry farms which are in successful operation to-day and make a careful study of their 
systems of management. You can learn not a little which will be of great service to you in so doing. And finally do not start in with three or five thousand fowls, but with a few hundred and gradually increase the number as experience in managing them enables you to do so profitably. You will find that you have to make a market for your eggs, and eggs are perishable property and must be sold when fresh. You will have a great deal to learn in caring for your flocks and in looking after the details of your business. If you commence with too many the chances are that, unless you are a very remarkable person, you will make a bad failure. But if you begin with a comparatively small number you can fit yourself for the easy management of a large business, and find that its details do not wear upon you any more than did the cares of your smaller business. A harness once perfectly fitted is easy to wear, but before the fitting is accomplished it is liable to chafe in spots and produce galls and lameness, and it is so with the harness of your business. Once fitted to you, you w:1l find it easy and pleasant to wear and will be surprised at the loads which you can draw without discomfort.

CONCLUSION.

We have traversed a pretty wide field. We have surveyed the various purposes which a poultryman may have; we have selected a breed suitable for the chosen purpose; we have studied the principles that should govern in the erection of a poultry-house and yard; we have considered the science of mating fowls for the production of young that shall be a credit to their progen. 
itors; we have glanced at the egg and the methods of transforming it into a living creature; we have explained the care that awaits with solicitude upon the tender days of chickenhood; we have set forth the principles which make up the philosophy of feeding; we have diagnosed the various poultry diseases and prescribed for the patients; we have entered the exhibition room with our feathered pets and carried away all the first prizes in our department; and we have considered the difficulties that lie in wait for the inexperienced who desire to raise poultry on a large scale. This is a pretty wide field to survey, and our glance at it necessarily has been a hasty one. Each topic touched upon in these pages, is large enough to demand for its proper treatment a discussion as extended as the space into which we have been obliged to compress all of them. But we hope that we have given a view of the field that will be of service; that from these pages may be learned enough to enable the would-be breeder to successfully rear from the egg to the exhibition room the breed which he has selected. We hope, however, that the reader will not rest content with this bird's-eye view, but that he will scrutinize each portion of this field in detail, until he has become familiar, not only with its general outlines and the relation of part to part, but also with all the elevations and depressions that belong to each part. In other words we hope that he will pursue his investigations until he has mastered the science of rearing poultry. Much has been written upon this subject that can be read with profit. There is no danger of reading too much. Danger lies in the opposite direction for all of us. 


\section{STODDARD'S}

\section{Twenty-Five Cent Poultry Books.}

\section{THIRTEEN POULTRY BOOKS!}

To meet the needs of inquirers regarding special poultry topics, we publish thirteen separate treatises, which we mail for 25 cents each, entitled:

“POULTRY DISEASES,"

"POULTRY ARCHITECTURE,"

"LIGH'T BRAHMAS,"

"WHITE LEGHORNS,"

"BROWN LEGHORNS,"

"PLYMOUTH ROCKS,"

"WYANDOTTES,"

“DOMESTIC WATER-FOWL,"

"INCUBATION ; Natural and ARtificial,"

" HOW TO RAISE POULTRY ON A LARGE SCALE,"

"HOW TO FEED FOWLS,"

"HOW TO IVIN POULTRY PRIZES,"

" HOW TO PRESERVE EGGS."

Any one of the above thirteen books mailed singly for 25 cents; any five for $\$ 1.00$, or ten for $\$ 2.00$; the whole thirteen books for $\$ 2.50$.

ADDRESS,

H. H. STODDARD, Publisher, HARTFORD, CONN. 



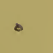


LIBRARY OF CONGRESS

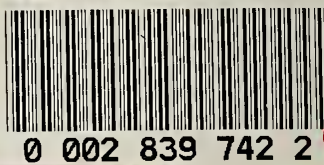

